Journal of Social Sciences 6 (1): 85-92, 2010

ISSN 1549-3652

(C) 2010 Science Publications

\title{
Philosophical Prostitution
}

\author{
Amihud Gilead \\ Department of Philosophy, Eshkol Tower, University of Haifa, Haifa 31905, Israel
}

\begin{abstract}
Problem statement: This research was needed because some philosophers were subject to a form of blindness concerning prostitution. This blindness was caused mainly by a lack of philosophical insights. The context of the work was that valid arguments without such insights must be blind. In the case of prostitution, I termed such blindness a philosophical prostitution: First of all, this was to indicate that such an opinion on prostitution was a philosophical artifact or fiction, entirely unaware of the reality in which prostitution can be possible, a reality in which prostitution inevitably entailed regular acts of rape. The second point I made was a moral one, which was even more pejorative. Conclusion/Recommendations: We should consider the problem of prostitution on quite different grounds in stark contrast with some prevalent philosophical views. Prostitution should be considered as the worse form of slavery. I could not find any philosophical argument that may justify slavery under any circumstances. Exploiting prostitutes should be considered as rape, which must be simply immoral and legally intolerable. Thus the pimps and the "clients" (actually, rapists) should be punished by law and exploiting prostitutes should be treated as strictly illegal.
\end{abstract}

Key words: Blind arguments, exploitation, insights, Martha Nussbaum, rape, slavery, Eliot Laurence Spitzer

\section{INTRODUCTION}

Blind arguments and philosophical prostitution: In this study, I would like to argue that some academic philosophers have committed a ruthless blindness concerning prostitution. This error consists of constructing of some valid arguments, which are actually blind to the reality in which we all, including prostitutes, live. This detachment from reality is caused also by lack of philosophical insights. Valid arguments that lack such insights are blind. In the case of prostitution, I term such blindness as a philosophical prostitution, first of all to indicate that such view on prostitution is a philosophical artifact or fiction, entirely blind to the reality in which prostitution is possible. The second sense is even more pejorative, of which I will speak later.

The personal motivation of such blind philosophers is not the real point I would like to make at this study. This motivation would be misinterpreted and, first and foremost, it is inaccessible in principle from without. Only the philosophers themselves can know what their real motives are in making philosophy and even that only in part, as there should be some unconscious motives to their doing. In any event, this study cannot discuss the motivation of these philosophers.

The distressing phenomenon that I attempting at pointing out in this study is typical of making arguments, which are entirely valid and certainly unsound, for they are blind to the reality, inner and external as well, in which these philosophers, like all of us, actually live. Their arguments are, in most of the cases, strictly valid but still lacking anything insightful; actually, they are blind, even stupid, arguments. Furthermore, some of these arguments are also against our best moral judgments. Think, for instance, of valid arguments as attempting at proving that slavery is legitimate, that machine can think, that persons can be duplicable and that there is no freedom of choice. The philosophers who make such arguments are well aware of the fact that they are counter-intuitive, which is legitimate in itself, but they wish to persuade the readers that our intuitions over these matters are simply wrong and should be considered as prejudices. Perhaps some or many of our common intuitions are actually wrong or simply prejudices and would they have been philosophically analyzed, they would have eventually revealed as such. Yet, our moral demands, or deep and fruitful insights, our long-established experience and the like should not be ignored or dismissed as simply crude intuitions (Gilead, 2004).

Perhaps the term "philosophical prostitution" would be sound harsh, politically incorrect, rude and the like and I could easily replace it for "alienating philosophy", "philosophy deprived of insights", or simply "blind philosophy", but the point is that some 
"moral" arguments are considered to be blind, for instance, to the fact that prostitution involved in the great majority of cases, if not in all of them, regular rapes of the prostitutes and, therefore, there is a excellent reason for the Swedish law that considers the clients as rapists that should be treated as criminals. Note that the rape in question has nothing to do with the stupid belief or prejudice about, what Nussbaum entitles, "the rapacious character of male sexuality" (Nussbaum, 1998). A philosopher who would attempt to justify some kinds of slavery by means of valid arguments, actually commits an immoral act. So are those who ignore the fact that in most cases of prostitution, if not in all of them, a regular rape is inescapably involved.

Nussbaum's view on prostitution as a paradigm case: As a paradigm case for philosophical immorality, a stance that clearly stands against human experience, sensitivity, insightful understanding and attention to reality as it is, I would like to consider Martha Nussbaum's stance in the question of the legalization or institution of prostitute (Nussbaum, 2000; 2008). Of course, she or some of her readers, would blame me for following some puritanical, even hypocritical, prejudices. But this will not do, as I am sincerely antipuritan, my devotion is to liberty and conditional liberalism, very much against sexual censorship, for freedom of thought and speaking, against any attempt to entangle state with religion, against most of the kinds of "politically correctness" and I am certainly for philosophical criticism, non-conformism, intellectual courage, avant-gardism and the like. Nevertheless, these works by Martha Nussbaum contain in them what I dare to describe as "philosophical blindness", of a view that is certainly immoral, blind to human distress, contaminated with academic philosophical sterility and clearly unwise.

Let us begin this somewhat furious discussion with the very beginning of Nussbaum's study:

All of us, with the exception of the independently wealth and the unemployed, take money for the use of our body. Professors, factory workers, lawyers, opera singer, prostitutes, doctors, legislators-we all do things with parts of our bodies for which we receive a wage in return (Nussbaum, 1998)

I, for one, a male philosophy professor, aggressively, categorically refuse to include myself in a group of workers in which prostitutes are "legitimately" included. I see no crime involved in philosophizing, in factory working, opera singing, medicine, legislation and the like. But I see horrible crimes from which almost any prostitute terribly suffered from her or his clients.

"Clients" is not the right term in this context, for, I argue, prostitution is not a profession, occupation, or way of life that is consists of clients and professionals or suppliers. Wife or husband surrogate has clients, which s/he professionally treats. Prostitutes, in contrast, have no such clients, but they are actually raped by those who used them for the aggressors' sexual gratification and pimps (whenever pimps are involved).

The unbridgeable gap separating all those professionals from prostitutes is that they make use their body, in which their bodies serve not as means only. Their bodies are not simply objects like any other object. In contrast, prostitutes give other the "permission" to use their bodies not as if they were bodies of persons, but as objects serving only for the sexual pleasure of others, who are demanded to pay for this pleasure. Moreover, the using of their bodies is involved with penetration. Penetration into the body of other person is permitted only if this body is respected as a body of a person, whose boundaries protecting her or him from the world without are well kept and respected. In other words, the penetration into the prostitute's body is simply a rape under the "consent" of the urgent needs of the prostitute to make her living in such a horrible way.

Nussbaum refers to the suggestion to relate prostitution to rape as the argument considering prostitution as involving the invasion of the prostitute's intimate bodily space (Nussbaum, 2000). But she, shamefully, argues that this "does not seem to support legal regulation of prostitution, provided that as the invasion in question is consensual" (ibid). Yes, it appears to be "consensual" because the miserable prostitute has no other choice, very much like the victim of a rape. She pays a horrible price for this "consent" in mental and physical terms. It is absolutely against her will, as no pleasure at all is involved in her sexual intercourse with her "clients"-rapists. Nevertheless, Nussbaum disgracefully continues:

In this sense, prostitution is quite unlike sexual harassment and rape and far more like the activity of the colonscopy artist-not to everyone's taste and involving a surrender of bodily privacy that some will find repellantbut not for that reason necessarily bad, either for the self or others. The argument does not even appear to support a moral criticism of prostitution unless one is prepared to make a 
moral criticism of all sexual contact that does not involve love or marriage (ibid)

Colonscopy artist is a person who let doctors and researchers to test means of medical inspection of the colon. These tests certainly involve the invasion of the colonscopy artist's intimate bodily space, but it is performed under full, legal and moral consent of the "artist". The results may help treating him or her in case of a needed colonoscopy in the future and in medically treating potential patients. Nothing in this case can be compared with prostitution. The invasion of a prostitute's body is never consensual, on the contrary, it is a rape to which the prostitute cannot refuse owing to the miserable mental, social and economical circumstances of her life. This invasion is involved with disgrace, humiliation, sense of a life's failure and devastating feeling of being worthless. It does not make anything good for humanity, for its health, for research and the like. In contrast, the case of colonoscopy's experiments is entirely different-it serves science, medicine and potentially helping patients, including these "artists" themselves. Finally, I have nothing against sexual relationship that does not involve love or marriage, as long as this relationship consists of real consent on the basis of mutual pleasure, satisfaction, relaxation and the like. In the above cited passage, any clever and sensitive reader can realize how great is the blindness of Nussbaum's view and argument concerning prostitution. She appears to know absolutely nothing about the miserable life of any prostitute, or simply to ignore this fact. Her arguments about prostitution are clearly detached from real life and, all the more, from human compassion, which prostitutes desperately need.

Undoubtedly, any prostitute would greatly prefer to make her living in quite a different way, like all of us do. Under the treat terrorizing her very existence, she is undoubtedly forced to sell her body and to be raped again and again. Any normal law should protect her effectively from such inhuman mistreatment, actually, from such crimes.

Finally, prostitution is the worse form of slavery. I see no philosophical argument that can justify slavery under any circumstances.

Difference between surrogate wives or husband and prostitutes: Let us compare prostitution with wife/husband surrogacy. In this case the surrogate lets the patients to use his or her body but in strictly different manner from that of any prostitution. Surrogate wives or husbands make help the patients to solve their sexual problems or dysfunctions. In this case the surrogate certainly does not let the patient to use his or her body as means alone without respecting his or her personhood and body. On the contrary, the surrogate uses his or her personality, his or her humanness, sensitivity, sympathy, empathy, knowledge and experience to help another human being. The relationship between them is certainly not as between an object and a person, but it is a sensitive, humane and helpful inter-subjective or inter-personal relationship, which is subject to professional values as well as human moral values. Thus, surrogacy is a part and parcel of medicine sciences. It is a therapeutic profession.

In contrast, a prostitute is not a doctor, nurse, physiotherapist, massagist, or health worker. As a prostitute, she has no profession at all. She is simply a means to satisfy the client's sexual desire. She does not take care of him and his benefit as such does not bother her at all. All she is interested with is his money. She wants the client to be satisfied of her services just to keep him as a source for her income. His health, wellbeing, or state of mind as such does not bother her at all, as long as he satisfies her financial needs. Prostitute/client relationship is by no means intersubjective; it is rather a relationship between means or objects-the prostitute is a means or an object to gratify the sexual satisfaction of the client and the client is a means to provide the prostitute with money, as much as possible.

A counter-argument: Given that prostitution is not a profession, still, you might counter-argue, women all over the world sell their bodies for financial and many others of their needs every night, at least most of the nights, in their husbands' beds. Thus many marriages do not rest anymore on romantic basis but on that of material and other needs or interests. So what is the point to exclude, even to excommunicate, prostitutes? This distressing phenomenon appears to be universal and to have many different forms and disguises, some of which are extremely misleading.

This counter-argument will not do. For in any of these cases, the relationship is between persons; it is inter-subjective or inter-personal. No rape has to be involved with them. Marriage, whether good or not, is an inter-subjective, inter-personal relationship; whereas prostitute/client relationship is between subject and some of his useful objects. Prostitution actually alienates anything personal or inter-personal. Were we succeeded in making a inanimate dolls, which would precisely behave and look like prostitutes in supplying the clients with all they need as clients of prostitutes and entirely satisfying their sexual needs, this would 
change nothing in the client/prostitute relationship. In contrast, wife and husband relationship, even in the most degenerate from and as a complete failure, are not like that. The misery of such relationship is precisely because the human factors, such as emotions, feelings, wishes, hopes, fear, frustration and the like are always there. Any marriage involves inter-subjectivity or interpersonality; not so prostitute/client relationship. The former is like the relationship between a person and the food s/he eats, or even between two objects.

Another counter-argument: This is a strange counterargument, but since I have heard it occasionally, I would like to refer to it. It goes as follows: Some distinguished persons, including academic professors, meet their would-to-be wives while sleeping with them as prostitutes. Some of these marriages have happened to be happy. If my assumption that prostitution necessarily entails rape, the counter-argument goes, this could not be the case. Is it reasonable or probable to argue that some happy marriages begin with rape? Given that there is no such a case, this argument is a sheer nonsense; at most the "argument" shows that prostitutes strongly prefer to relinquish this horrible way of life or way of making a living. Instead, they greatly prefer marriage, happy children, respectful life, descent way of living and the like. Because prostitute is a sort of slavery and it necessarily entails rape, any prostitute prefers quite a different life. The "argument" turns to be an argument against prostitution, not for it! Especially, it is an argument against the clients of prostitutes. It shows that normal, moral and healthy relationship between men and women absolutely cannot rest on prostitution.

For what reason did my family doctor make her manager so angry? To re-demonstrate in a concrete way that prostitution is not an occupation or profession, I would like to suggest the following example. My family doctor, an excellent general practitioner, used to complain very much about the rule in her clinic, according to which she is entitled to allocate only 10 min for each examination of each patient. "Even in Britain nowadays, a GP has $15 \mathrm{~min}$ for each examination, in which s/he has not to perform any administrative job, which only the medical secretary does. Now, I demanded the person in charge, my boss, who is, too, MD, to allocate me at least $5 \mathrm{~min}$ more for each examination of any of my patient. He absolutely refused. Having suggested him all the arguments I could muster, I finally decided to rely on the last one as follows: Any prostitute, who treats only one organ of her clients, usually needs more, even much more, than
10 min to satisfy him, whereas I, who is responsible for all the patient's organs, have at most $10 \mathrm{~min}$ to do my job, which is certainly improper". The manager reacted very angrily and shouted at her: "How dare you, my dear and old colleague, to make such a nasty and silly comparison between our sublime profession and prostitution? Have you become mad because you wrongly believe that any patient needs for more than 10 min?"

What made him so mad was precisely the comparison between making one's living that has nothing to do with a most distinguished profession, which requires a lot of knowledge, science, learning, skill, training and long experience. Although the doctor uses his body, senses, observation and the like to diagnose the patients' condition and to treat them, no one is entitled to compare her to a prostitute.

What my doctor attempted of achieving is to persuade the manager that to allocate only $10 \mathrm{~min}$ for an examination of a patient is a sort of prostitution, by no means an examination that any professional, especially a descent general practitioner, may follow. Under such circumstances, no medical treatment is worth of its name and it turned to be like prostitution. This simple common knowledge, perhaps insight, appears to be inaccessible for some philosophers nowadays, only because these philosophers are entirely blind to the reality in which we actually living. Happy, professional hookers exit only in fictional literature, most of the time in sheer pornographic fantasies. Such pure possibilities of happy and descent hookers, are not actual at all.

"The prostitute and the professor of philosophy": Nussbaum writes:

These two figures have a very interesting similarity: Both provide bodily services in areas that are generally thought to be especially intimate and definitive of selfhood. Just as the prostitute takes money for sex, which is commonly thought to be an area of intimate self-expression, so the professor takes money for thinking and writing about what he thinks-about morality, emotion, the nature of knowledge, whatever-all parts of a human being's intimate search for understanding of the world and self-understanding. It was precisely for this reason that the medieval thinkers ...Saw such a moral problem about philosophizing for money: It should be a pure spiritual gift and it is degraded by the receipt of a wage. The fact that we do not think that the professor... Thereby alienates her mind or turns her thoughts into commodities-even when she 
writes a paper for a specific conference or volumeshould put us on our guard about making similar conclusions in the case of the prostitute (Nussbaum, 1998)

This sounds as a complete nonsense to me. No prostitute gives something of her spirit, something of herself. No prostitute is involved with an intimate relationship. She lends her body for a stranger's usage for a short while or on another temporal basis. No professor of philosophy should be physical or mentally invaded in order to provide her students with her wisdom and knowledge. And, first and foremost, there is no intimacy whatsoever between prostitutes and their clients. This is only, at most, a fake of intimacy, by no means a real one. If both "figures" employ their bodies to do their job, the two kinds of bodily employment or usage are absolutely different. Finally, if someone believes that taking money for philosophical professorship is disgraceful, one is entitled to call it "prostitution", but this is only a metaphor, which should be radically distinguished from any real, actual prostitution.

Humiliation: All the examples, except prostitution, in Nussbaum's opening clause mentioned above do not necessarily or inescapably involve humiliation; not so prostitution. It necessarily and inescapably involves humiliation, undoubtedly that of the prostitute, but, under different form, also that of the client, too. If he attempts at buying something that cannot be buy, especially love, this actually deceives and humiliates him, consciously or unconsciously, as a undignified human being. Prostitution is shameful first and foremost insofar as the client-rapist is concerned.

At this point, I should agree with the claim that the stigma of prostitution is unfair. It is not fair at all to excommunicate prostitutes or to derogate them. As victims of rapes, they should be treated as morally innocent and as deserving of protection, treatment and care, as humanly as possible.

It is the blame, even the crime, of the client that Nussbaum entirely ignores. She mentions the case of "Eliot Spitzer, one of the nation's most gifted and dedicated politicians, (who) was bounded into resignation by a Puritanism and mean-spiritedness that are quintessentially American" (Nussbaum, 2008).

Eliot Laurence Spitzer is an American lawyer and a former politician of the Democratic Party. J Dr. Spitzer used to be New York State Attorney General. As the Governor of New York City from 2007 until 2008, he finally resigned because of his involvement in being a client of a prostitutional ring for a long time and for a lot of money. The scandal was exposed on March 10, 2008 by The New York Times. Spitzer reasoned his resignation in these words: "I cannot allow for my private failings to disrupt the people's work. Over the course of my public life, I have insisted-I believe correctly-that people take responsibility for their conduct. I can and will ask no less of myself. For this reason, I am resigning from the office of governor". If he himself describes this as "private failings" that should not disrupt the public work, why should we believe that only because of American Puritanism he was persecuted? Private failing should not disrupt the public management at all, unless it significantly reflects public significance, which is the case of JDr Sptizer.

First and foremost, Spitzer was not persecuted because of any typically American Puritanism and mean-spiritedness, but only because he broke the law, the very same law that publicly he used to enforce! And the stigma in question is not, or should not be, on prostitutes, who are victims that need protection and help, but on the client! Nussbaum appears not to consider this stigma, better, blame or crime, at all. She appears to be entirely blind to the grave suffering, bondage, poverty, deterioration, mental illness and slavery that prostitutes are the victims of, including the "most fortunate" of them. They are not only victims of pimps, but, first and foremost, of the clients-rapists. Precisely in these two respects, they need the protection of the law against their aggressors. That is, not puritanical laws against prostitution as an undesirable phenomenon, but human and justified laws against the pimps and the clients as well are relevant in this case. Otherwise, the modern state does not implement at all one of its firm duties-to protect the citizens as much as possible against any danger of epidemic, death, catastrophes, rape, murder, slavery and other evils done by human beings to other human beings. As prostitutes' client, Eliot Spitzer should be persecuted by the laws that protect prostitutes from people like him. Nevertheless, some blind philosophers allow themselves to simply ignore that crucial fact of the matter.

Blindness in this context is simply euphony. I permit the reader to use other terms, such as stupidity, immorality, superficiality, or insensitivity. I am even tempted to call it simply philosophical prostitution. As prostitutions' clients and pimps are certainly blameful and punishable, no less shameful is the attempts of white-washing them. Nussbaum simply attempts at white-washing Eliot Spitzer and other prostitutes' clients. She should be treated like anyone who attempts of justifying slavery, racism, rape and other crimes against human dignity. To remove any 
misunderstanding, I do not justify any legal act against any form of expressing opinion, especially not in the case of philosophy. Nevertheless, I consider Nussbaum's stance about prostitution as a landing mark in the closing, decay, or deluding of the American philosophical mind, for she is not the only one subject to philosophical blindness. Her case is certainly one of the worse.

Hypocrisy and prostitution: Indeed, our society is hypocrite concerning prostitution, but by no means because of the reasons that Nussbaum and her likes think of. The hypocrisy concerns the clients, in considering them as normal males who are entitled to satisfy their sexual needs by paying for them. Instead of blaming the pimps and the clients alike for a crime against women, the hypocrite society blames first of all the prostitutes and secondly the pimps, as if nothing is wrong with the client. Suppose that one would dare to blame the raped women for the rape. All of us, civil persons, would seriously object and we would blame him or her harshly. In cases that prostitutes are actually raped several, even many, times per day and night, these hypocrites blame the prostitute for being raped! To blame the victim for the crime that the aggressor and the criminal have done to her, is just immoral, deceptive and simply evil.

Exploitation, rape and more about the current slavery: Now, would a counter-argument suggests, suppose that the current exploitation all over the world, in which workers, many of them are certainly workaholics, can be revealed as the current slaves. For instance, the high-tech industry, which consumes much of the energy of the employees, most of their time, when neglecting their private time with wives, spouses and children. Is this not slavery, a disguised one? Not to mention the million of workers in China. So what is the fuss about the slavery involved in prostitution?

My late dear brother, younger than me in two and half years, is dead by now because of heart failure. I am suffering from the same problem but still alive and kicking. Given that we shared a similar heredity and our family life and career flourished, the only explanation I have for his untimely death is his hard work. My late brother used to be a high-tech employee, a deputy manager of one of the largest high-tech industries in Israel and one of the best in the world. This means that he had to work around the clock, never getting real rest and his family life had to be at the second place. Is such a work not even worse than some forms of slavery, such as prostitution? After all, one may easily refer to "happy hookers", who earn their living in this way quite willingly. Notwithstanding, such is not the situation at all, for while my brother chose his way of life absolutely willingly, prostitution is never like that; while no normal, sane person wants himself or herself to be humiliated, prostitution cannot avoid humiliation. The point is not only that exploitation, even relating to one as an object or means only, is common to workaholism and prostitution, the point is that workaholism does not necessarily involve humiliation, whereas prostitution cannot avoid it. Moreover, again, prostitution inescapably involves rape, for no prostitute let her clients to enter her body out of desire or love alone, which makes it a rape. Sexual relationship that does not rest on passion, desire, love, or wish for giving birth to child/children of both partners, is involved with this or that kind of rape. In other words, such relationship is very much against the will of the prostitutes, whether $\mathrm{s} / \mathrm{he}$ is aware of this or not.

In sum, exploitation, even complete exploitation or current slavery under disguise, of one's body is not the main point about prostitution, which involves complete ignoring of the humanity in each of us. No prostitution can be dignified and any prostitution is a shame, an ignorant of the humanity in each of us.

Sympathy and liberalism: This study demonstrates sympathy with the prostitutes, not with the clients or the pimps. We should not be liberal with prostitutes' clients and pimps; we should not tolerate them. Rather the contrary, we should punish them quite severely.

As it is well known, the liberty of wolfs entails the death of the lambs. To tolerate pimps and prostitutional clients and to let them have their liberty means the horrible slavery and rape of the prostitute. We should not tolerate that; we should not be liberal with these oppressors.

At least in our society, prostitution and the oppression of the prostitutes go hand-in-hand:

Although the commercial availability of sexuality is not in every existing or conceivable society oppressive to women, in our society this practice depends upon the general acceptance of principles which serve to marginalize women socially and politically. Because of the cultural context in which prostitution operates, it epitomizes and perpetuates pernicious patriarchal beliefs and values and, therefore, is both damaging to the women who sell sex and, as an organized social practice, to all women in our society (Shrage, 1989) 
Nussbaum and others probably assume that the stance that I advocate here is not liberal and it intolerably treats sexual relationship that should be kept far behind lawful sanction and political control. I am certainly for absolute liberty from religious institution and puritanical judgment, which should be kept far behind public affairs and reality. What people do with their sexual life and bodies is strictly their private matter. But whenever somebody is hart or threaten by the sexual behavior of somebody, we should give the potential and actual victim of this behavior an effective protection by means of strict laws.

Yes indeed, prostitutes are entitled to do whatsoever they like with their bodies. They are entitled to be prostitutes. But this does not means that we allow the clients and pimps to be their clients and pimps. If this may render prostitution simply impossible, so good for it. We would like prostitutes to be liberated, to be responsible for their bodies and choices, but we do not want their clients and pimps to enjoy such a freedom or liberty in the case of prostitution.

Note that the general view I am advocating permits abortion. If the reader believes that the fetus has the right to be born and to exist, my answer is that first of all it is the right of the potential mother to do with her body whatsoever she likes to do with it. As for the fetus, undesirable, enforced child must be an unhappy one and it is much better for him or her not to be born at all. At least at this point, my liberalism is certainly consistent.

Capability of buying anything: One of the horrible aspects of prostitution is the belief shared by the clients that they can buy everything-love, any kind of sexual gratification, sense of power and domination and the like. This belief involves a whole worldview. According to it, one can buy everything, if one has enough resources to do so. This worldview is precisely that of torturers. They assume that since everything has a prize, under horrible torture, everybody will confess or do whatsoever the torturers want him or her to confess or to do. Prostututional clients believe precisely something like that-owing to their money they can dominate the prostitute absolutely and owing to it and to their capability of making money, they can use her like a sheer means to gratify their passions.

This is the dehumanization that is typical of prostitution. People should be harshly punished for such dehumanization. Such people are undoubtedly the prostitutional clients, let alone the pimps. Again, it is the prostitute that is the victim and all the blame must be upon those who rape her, who trade with her body and who pay for it.

Legalization: Pimps are not business persons. Like drugs dealers, they are criminal. We live in an absurd world in which drugs dealers, weapon agents and other monsters are not supposed to be regard as evil persons worth of severe punishment. It is not an accident that some wrong-headed minds, including philosophers, demand a legalization of prostitution, no less than weapon trade or agency is quite legitimate all over this miserable world. To distinguish wrong from right, good from bad, one needs a judgmental capability. Philosophers who demand for the legalization of prostitution, have lost this capability or simply have ignored or forgotten it.

Excommunication: No prostitute should be excommunicated on the basis of her way of life. In contrast, those who call themselves philosophers and, nevertheless, justify slavery, prostitution, or not condemning its clients and protecting them against criminal charge, should be harshly criticized. I am sorry to blame Martha Nussbaum for such a shame, but her view concerning prostitution, especially its clients, justifies such a criticism and even blame. Moreover, it clearly shows how academic philosophy has been degenerated owing to alienation and ignorance of human insights, feelings and experience. In such cases, it becomes even a stupid philosophy, no less than immoral and disgraceful.

Ironically, Nussbaum believes herself to listen to some insight: "Why were opera singers stigmatized? If we begin with this question, we can move on to prostitution with expanded insight. Throughout much of the history of modern Europe-as, indeed, in ancient Greece-there was a common aristocratic prejudice against earning wages" (Nussbaum, 1998). This move is totally blind to the distress of actual prostitution, which has nothing to do with that aristocratic stupid prejudice, according to which even eminent scientists, painters, sculptures, writers, poets and philosophers should not earn wages, which have made possible for them not only to make their living but also to continuing in creating novelties. Unlike prostitution, no rape, humiliation and disgrace have been attached to such occupations, professions, or ways of life and making living. And if the aristocrats really have deemed earning wages as disgraceful, nothing could be compare in disgrace with prostitution, which has made it a real exception, a phenomenon of sui generis. In any event, Nussbaum analysis of prostitution is clearly blind, lacking any enlightening insight and severely 
detached from the actual miserable life of prostitutes all over the world.

I can imagine that prostitutes all over the world would raise their voices against such a philosophy. First of all, we, philosophers, should be human, which certainly commits us not to ignore the human victims all over the world. We should raise our voice for helping prostitutes to choose other ways of life and living and not for protecting their disgraceful clients, as Nussbaum and some of her colleagues attempt to do.

Nussbaum's failure over this matter is not only philosophical; it is a moral failure, too. I hope that the number of such shameful failures will be diminished more and more.

Philosophical prostitution: Nussbaum cites a brilliant passage from Adam Smith's ideas concerning: "some very agreeable and beautiful talents of which the exercise for the sake of gain is considered, whether from reason or prejudice, as a sort of publick prostitution" (Smith, 1979). Smith points out the stigma that attached to singers and actors, because of which they would be treated like prostitutes, but Nussbaum mistreats Smith's analysis of this stigma, for real prostitution is inescapably involved with rape, humiliation, disgrace and other miseries, which has not been the case of singers and actors even in the days of Smith. Many singers and actors have been deemed quite highly; no prostitute as such ever has been deemed so, except when used for religious purposes and in this case, they did not named or considered as prostitutes at all. As implied from what I have argued above, it is not a matter of prejudice but for good reasons that I am entitled to argue that the view that prostitution is an occupation or profession like any other is a sort of philosophical prostitution. For the name of alleged novelty and expanding the philosophical possibilities, in the name of freedom from prejudices and unexamined assumptions, philosophers, such as Martha Nussbaum, allow themselves to express such views that are totally blind to the unbearable distress of the great majority, if not of all, the prostitutes all over the world that are raped and re-raped for many times almost in each day. It is a grave misuse of philosophy, a sort of philosophical prostitution, which is quite shameful and which has no justification at all. It is a blind philosophy, lacking insights and human empathy or humane feelings. If Nussbaum's arguments are valid, they are certainly blind, even stupid. The distress of the current situation in academic philosophy, especially in American and Britain, is that there are quite a lot of blind arguments, lacking insights and which are stupid indeed.

\section{CONCLUSION}

We should consider the problem of prostitution on quite different grounds in stark contrast with some prevalent philosophical views. Prostitution is the worse form of slavery. I see no philosophical argument that can justify slavery under any circumstances. Exploiting prostitutes should be considered as rape, which must be simply immoral and legally intolerable. Thus the pimps and the "clients" (actually, rapists) should be punished by law and exploiting prostitutes should be treated as strictly illegal. Yet the stigma of prostitution is unfair. It is not fair at all to excommunicate prostitutes or to derogate them. As victims of rapes, they should be treated as morally innocent and as deserving of protection, treatment and care, as humanly as possible. The view that prostitution is an occupation or profession like any other is a sort of philosophical blindness or prostitution.

\section{REFERENCES}

Gilead, A., 2004. Philosophical blindness: Between arguments and insights. Rev. Metaphys., 58: 147-170. http://www.jstor.org/pss/20130426

Nussbaum, M.C., 1998. Whether from reason or prejudice: Taking money for bodily services. J. Legal Stud., 27: 693-724. http://www.journals.uchicago.edu/toc/jls/27/s

Nussbaum, M.C., 2000. Sex and Social Justice. Oxford University Press, Oxford, ISBN: 0195112105, pp: 488.

Nussbaum, M.C., 2008. Trading on America's puritanical streak. http://uchicagolaw.typepad.com/faculty/2008/03/m artha-nussbaum.html

Shrage, L., 1989. Should feminists oppose prostitution? Ethics, 99: 347-361. http://www.jstor.org/stable/2381438

Smith, A., 1979. An Inquiry into the Nature and Causes of the Wealth of Nations. Clarendon, Oxford, ISBN: 0865970084. 